Article

\title{
Low-Carbon Energy Planning: A Hybrid MCDM Method Combining DANP and VIKOR Approach
}

\author{
Ruijun Liu ${ }^{1}$, Hao Sun ${ }^{1}$, Lu Zhang ${ }^{1}$, Qianwei Zhuang ${ }^{2, *}$, Lele Zhang ${ }^{3, *}$, Xueyi Zhang ${ }^{1}$ \\ and Ye Chen ${ }^{3, *}$ \\ 1 Transportation and Vehicle Engineering College, Shandong University of Technology, Zibo 255000, China; \\ liuruijun66@sdut.edu.cn (R.L.); zhompson@163.com (H.S.); zhuangqw17@mails.jlu.edu.cn (L.Z.); \\ zhangxueyi@sdut.edu.cn (X.Z.) \\ 2 College of Biological and Agricultural Engineering, Jilin University, Changchun, China \\ 3 Transportation College, Jilin University, Changchun, China \\ * Correspondence: wsxzhuang@163.com (Q.Z.); zll6226@163.com (L.Z.); cheny0818@126.com (Y.C.)
}

Received: 1 November 2018; Accepted: 30 November 2018; Published: 4 December 2018

check for updates

\begin{abstract}
With the development of urbanization, people's living standards have improved. Simultaneously, the growing aggravation of resource shortages and environmental pollution have also gradually attracted widespread attention. Low-carbon energy planning can effectively reduce dependence on fossil resources and carbon emissions to the atmosphere, as well as improve the utilization of resources. Therefore, the formulation and evaluation of low-carbon energy planning have become the focus of attention for related colleges and institutions. This paper puts forward a hybrid multi-criteria decision making(MCDM) method combining decision making trial and evaluation laboratory(DEMATEL), analytical network process(ANP), and VIKOR to obtain the weight of each criterion and evaluate each alternative about low-carbon energy planning for building. A hierarchy structure of criteria involving cost, safety, reliability, and environment protection is built. Afterwards, a case of four alternatives is applied for testifying this methodology. Lastly, a comparison with prior methodologies serves as proof of the raised ranking. The presentation has proved that this methodology offers a more precise and effective foundation for decisions about low-carbon energy planning evaluation.
\end{abstract}

Keywords: low-carbon; sustainability; MCDM approach; energy planning; building

\section{Introduction}

With the increased development of the modern global economy, energy shortages and environmental impact have become a focus of attention all around the world. Thus, Sustainable development (SD) vigorously promotes the progress of economic development [1-4]. This was first proposed by the Brundtland Report that satisfied the needs of the then current situation without compromising on future needs in 1987 [5]. Subsequently, SD has been gaining government and public momentum. The 2015 United Nations Development Summit released the formal statement, "Transforming our world: The 2030 agenda for sustainable development", including the sustainability of economy, society, and environment, in order to eliminate global poverty and make a dignified life for all. In the G20 leadership conference, sustainability in the global economy is seen as a serious problem. A series of measures and initiatives on sustainability and energy management have been put forward, e.g., joint work plan. Furthermore, a great deal of literature and research has emerged over the past few years [6-8]. Bansal et al. [9] operationalized corporate sustainable development and examined its organizational determinants. Dincer et al. [10] explained the relationship between energy and energy, 
energy and environment, energy and sustainable development, and moreover, energy policy formulation and energy detail.

Currently, deciding how to stimulate SD and mitigate the impact of human life on the environment has aroused widespread international concern. Among the range of solutions, the model of low carbon development designed to lower carbon emissions has been widely accepted, and is also a thoughtful target of human SD. At the Paris Climate International Conference in 2015, China announced that it was committed to reducing carbon emissions by $60 \%$ to $65 \%$ from 2005 levels by 2030 . The concept of low-carbon has been rapidly promoted in various fields, particularly in the energy industry. Liu et al. [11] presented the main problems of energy and low-carbon development that may be encountered in the next 50 years. Tsai et al. [12] investigated how low-carbon energy affects the growth of fuel consumption, to assess the feasibility of using low-carbon energy sources to displace fossil fuel energy in order to reduce carbon dioxide emissions. Liu et al. [13] presented a novel hybrid solar heating system and determined the optimal operation mode for improving the indoor thermal environment. Lugaric et al. [14] presented a decision-making framework to analyze energy management which integrates energy, economic, and environmental factors.

In recent years, environmental protection departments have emphasized the evolution of low-carbon energy, and related experts have studied it. Based on previous literature and research, the research direction can be summarized in two strategies. The first is the use of renewable energy technologies, e.g., wind power, hydropower, photovoltaic, and geothermal energy, to decrease carbon emissions. The other is the design and use of low-carbon energy planning to ensure adequate power capacity and to configure a variety of power forms reasonably. However, the best method to evaluate the quality of low-carbon energy planning that leads to a multi-criteria decision making (MCDM) issue has already been widely discussed; such a method must consider cost, safety, reliability, and environmental protection in the hierarchy structure of the criteria. Therefore, the method of dealing with the MCDM problem is particularly important. Nowadays, two types of methodologies are applied to resolve MCDM problem: (1) series assessment methodologies, e.g., MAUT [15], improved TOPSIS [16,17], AHP [18], DEMATEL-VIKOR [19-22], grey relational analysis (GRA) [23-25], etc., and (2) the LCA-based methodologies [26]. Furthermore, there are several integrated ways to make up for the defects of applying a single method, e.g., Kano-AHP and M-TOPSIS [27], DEMATEL-Analytical network process (ANP)-TOPSIS [28], and AHP-SWOT [29].

The purpose of this article is to develop appropriate technology to rationally evaluate the quality of low carbon energy planning. As a result of this complex decision, there are a few evaluation criteria that cannot be ignored. A hierarchy structure of criteria is built which involves cost, safety, reliability, and environmental protection. Additionally, a mixed MCDM methodology that integrates DEMATEL, ANP, and VIKOR (DANP-VIKOR) is proposed for getting each criterion's weight which evaluates each alternative for low-carbon energy planning, whereby DEMATEL is applied to analyze the influence degree of each criterion, and ANP can obtain each criterion's final weight. A case including four alternatives is applied to verify this mixed methodology.

The structure of this article is as follows. The following section summarizes some related literature. The third part describes the proposed means. The means are elaborated in the forth section. Analysis and discussion are conducted in the fifth part. The last part concludes this work.

\section{Literature Review}

This section is divided into three parts. The first subsection describes research focusing on sustainable development. The second subsection introduces possible methods used to evaluate the quality of low-carbon energy planning, in other words, the multi-criteria decision making (MCDM) issue. Some research gaps are described in the third part. 


\subsection{Research on Sustainable Development}

Positive relationships are demonstrated between sustainable development and economic growth [1-4]. This viewpoint, that satisfied the requirements of the then current situation without compromising on future needs in 1987 [5], was first proposed by the Brundtland Report. Subsequently, sustainable development has been starting to receive further government and public attention. For instance, the 2015 United Nations Development Summit and the G20 leadership conference have been focusing on sustainability in the global economy, society, and environment. As a result, a series of measures and initiatives on sustainability and energy management have been put forward, e.g., a joint work plan. Furthermore, a significant amount of related literature and research has emerged over the past few years [6,7]. Liu et al. [2] proposed that transdisciplinary sustainability research is practical for addressing sustainability challenges because it is able to integrate the best available knowledge, reconcile values and preferences, as well as create ownership for problems and solution options. Katia et al. [3] described a vision of sustainability research and presented an evaluative scheme for measuring its effectiveness, determining areas for improvements. Viagas et al. [4] addressed the existing lack of depth and comprehensiveness by identifying and categorizing the critical attributes of Sustainability in Higher Education. Ding et al. [8] measured the SD level of 287 prefecture-level cities as well as analyzing their dimensional distribution. Bansal et al. [9] operationalized corporate sustainable development and examined its organizational determinants. Dincer et al. [10] explained the relationship between energy and energy, energy and environment, energy and sustainable development, and energy policy formulation and energy detail. The concept of low-carbon has been rapidly promoted in various fields, particularly in the energy industry. Liu et al. [11] presented the main problems of energy and low-carbon development that may be encountered in the next 50 years. Tsai et al. [12] investigated how low-carbon energy affects the growth of the fuel consumption, to assess the feasibility of using low-carbon energy sources to displace fossil fuel energy in order to reduce carbon dioxide emissions. Yu et al. [13] put forward an assessment analysis of the low-carbon energy investment prospect. Lugaric et al. [14] presented a decision-making framework to analyze energy management which integrates energy, economic, and environmental process factors.

\subsection{Methodologies of Multi-Criteria Decision Making}

We have been highly focused on deciding how to evaluate the quality of low-carbon energy planning, which results in a multi-criteria decision making (MCDM) issue in a hierarchical structure of criteria. Therefore, selecting or designing an appropriate method of dealing with the above MCDM problem is crucial. Prior research of resolving the MCDM problem can be classified into two categories: one is series assessment methodologies, and the other is LCA-based methodologies [26]. There are several studies of the first category. Roth et al. [15] put forward the multi-attribute utility analysis (MAUA) as a powerful tool for materials selection and evaluation, and it has been used in a wide range of engineering areas. Rao et al. [17] presented a logical procedure for material selection for a given engineering design based on a combined TOPSIS and AHP method. Shahabi et al. [18] identified ten related factors by using a statistical model including the analytical hierarchy process (AHP). Prasenjit et al. [19] attempted to solve the robot selection problem using VIKOR, and compared their relative performance for a given industrial application. Serkan et al. [22] established a fuzzy DEMATEL-based solution approach which takes into account both qualitative and quantitative location factors for addressing the facility layout problem. Joseph et al. [24] used grey relational analysis to propose the multi-criteria weighted average in the decision-making process to rank the materials concerning several criteria. There are several studies regarding the LCA-based methodologies. Taflanidis et al. [26] presented a systematic probabilistic framework for detailed estimation and optimization of the life-cycle cost of engineering systems. Avikal et al. [27] applied a Kano model, fuzzy-AHP, and M-TOPSIS-based technique to find the optimal order of component removal using AND/OR precedence relation. Govindan et al. [28] proposed a model to evaluate the best sustainable construction material based on sustainable indicators through a hybrid 
multi-criteria decision making (MCDM) methodology with the integration of DEMATEL, ANP, and Topsis. Finally, Tavana et al. [29] firstly identified the relevant criteria and sub-criteria using SWOT analysis and then used Intuitionistic Fuzzy AHP to evaluate the relative importance weights among the criteria and the corresponding sub-criteria.

\subsection{Research Gap}

By summarizing and analyzing the existing research results, two main conclusions can be drawn. Firstly, a comprehensive hierarchy structure of criteria for the quality evaluation of low-carbon energy planning has not been constructed by prior research, which has ignored some evaluation criteria such as reliability, environmental protection, etc. Secondly, methodologies applied to the MCDM issue usually adopt the normalization approach for the hyper-matrices, which is considered to be unreasonable as every bunch from the distribution of each norm in the column obtained the same weight in the customizable course [30].

Compared with some current research, this paper makes two major contributions: (i) Regarding the lack of comprehensive evaluation systems, a hierarchy structure of criteria is built which involves cost, safety, reliability, and environmental protection. (ii) To raise an appropriate method for the evaluation issue of this work, a mixed MCDM methodology that integrates DEMATEL, ANP, and VIKOR (DANP-VIKOR) is proposed for getting each criterion's weight and evaluating each alternative which is about low-carbon energy planning, where DEMATEL is applied to analyze the influence degree of each criterion, while ANP can obtain each criterion's final weights. A case including four alternatives is applied to verify this mixed methodology.

\section{Background and Problem Description}

This research aims to evaluate the quality of low-carbon energy planning more objectively and rationally. The introduction concentrates on the low-carbon energy planning and hierarchy structure for evaluation criteria.

\subsection{Low-Carbon Energy Planning}

$\mathrm{CO}_{2}$ accounts for $77 \%$ of greenhouse gases (GHG). GHG emissions have resulted in climate change and continue to present a significant threat to humanity [31-33]. In China, growing energy consumption and coal-dominated energy construction have caused rapid increases in carbon dioxide emissions over the past 45 years. The burning of fossil fuels in China have led to an increase of carbon dioxide emissions from 4.8 billion tons in 1965 to 8.7 billion tons in 2011, making up 25\% of the world's total [34]. Hence, the increasing low-carbon economy has become a significant trend in China. Several policies, e.g., the Renewable Resource Regulation, executed in 2006; the National Development Plan for Renewable Resource and Energy, issued in 2007; and the 13th Five-Year Renewable Energy Development Plan, have been formulated to boost the development of low carbon economies in 2017.

The identification of renewable, clean, environmentally-sustainable energy resources is the great challenge of our times [35]. Currently, renewable energy generation has been the main trend to facilitate the development of a low-carbon economy. However, there are several problems which have to be solved in the energy development process. The first is that renewable energy, e.g., biomass energy [36], wind power, hydropower, photovoltaic, and geothermal energies are inefficient. Although carbon capture and storage as a common technology can effectively reduce $\mathrm{CO}_{2}$ emissions from power plants, it is only based on non-renewable energy resources. Therefore, combining renewable energy and low-carbon capture and storage technology is necessary to promote a low-carbon economy. Additionally, one of the elements in energy planning is to determine the most economical energy investment program and ensure the reliability and safety of electricity. But under the guidance of low-carbon economic development, several environmental factors, e.g., $\mathrm{CO}_{2}$ emissions and $\mathrm{SO}_{2}$ 
emissions must be properly considered in the planning process. Thus, the study of low-carbon energy planning has been conducted by Chinese and western researchers [37-39].

\subsection{Hierarchy Structure for Evaluation Criteria}

Evaluating the quality of low-carbon energy planning is an MCDM problem which must consider several different types of criteria, e.g., cost, safety, reliability, and environment protection [40]. Therefore, in view of relevant document and specialist discussion, this paper creates a stratum of assessment process, as demonstrated in Figure 1, which consists of goals, criteria, and attribute levels. Goal level $(B)$ is low-carbon energy planning assessment; criterion one $(E)$ is reliability $\left(E_{1}\right)$, safety $\left(E_{2}\right)$, economy $\left(E_{3}\right)$, and environmental properties $\left(E_{4}\right)$. The Reliability feature encompasses four factors, namely, power shortage expectations $\left(C_{1}\right)$, power shortage frequency $\left(C_{2}\right)$, duration of power shortage $\left(C_{3}\right)$, and low battery expectations $\left(C_{4}\right)$. Safety features constitute four factors, namely, power load matching degree $\left(C_{5}\right)$, the proportion of intermittent energy $\left(C_{6}\right)$, positive peaking capacity $\left(C_{7}\right)$, and the proportion of outside electricity $\left(C_{8}\right)$. The Economy feature comprises four factors, namely, investment costs $\left(C_{9}\right)$, operating costs $\left(C_{10}\right)$, plant electricity rate $\left(C_{11}\right)$, and carbon emissions costs $\left(C_{12}\right)$. The Environmental feature comprises three factors, i.e., proportion of renewable energy $\left(C_{13}\right)$, $\mathrm{CO}_{2}$ emissions $\left(C_{14}\right)$, and nitrogen oxide emissions $\left(C_{15}\right)$.

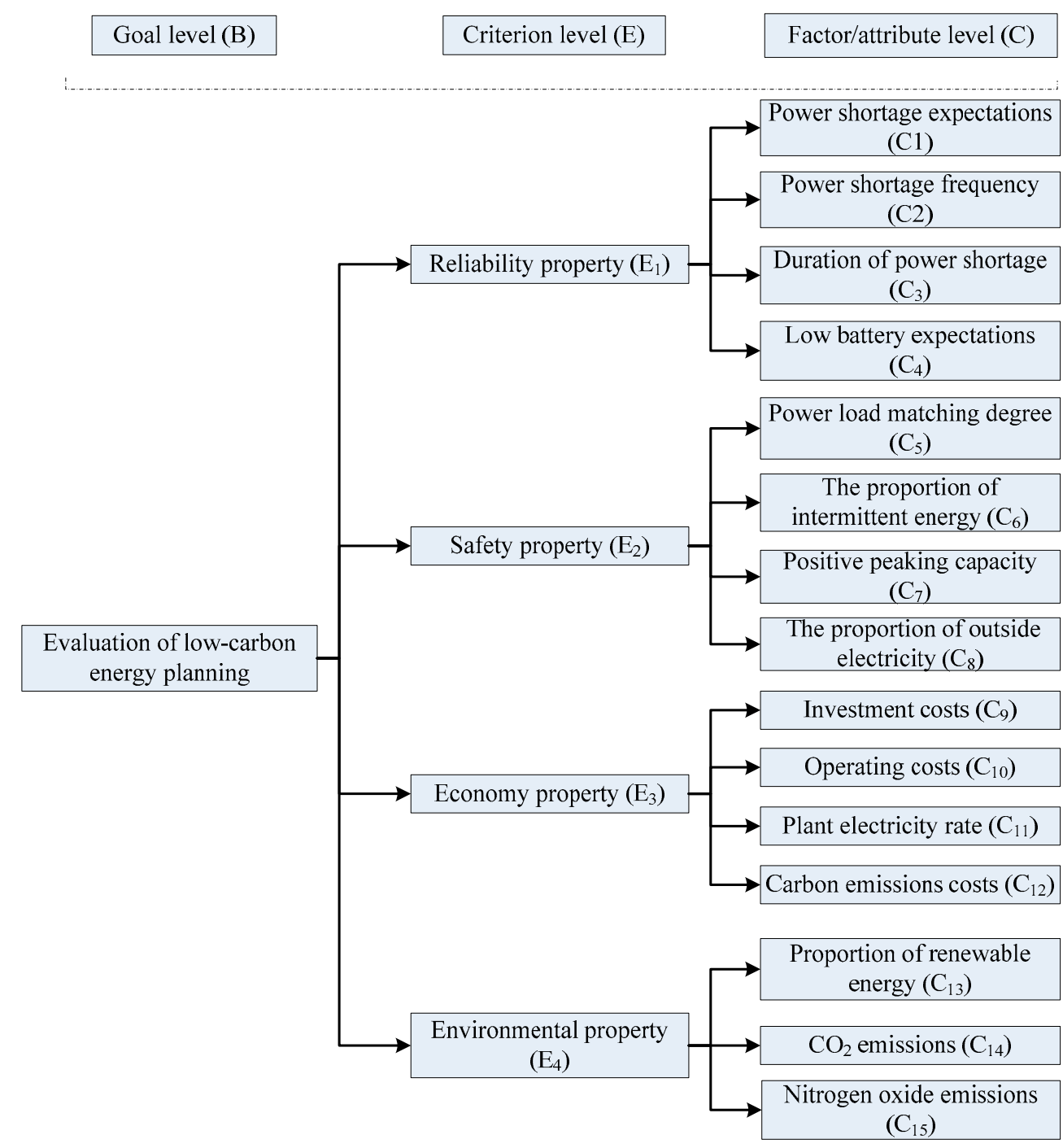

Figure 1. A hierarchy structure for the evaluation of low-carbon energy planning. 


\section{Methodology}

A mixed MCDM method including DANP with VIKOR is a way that assesses the quality of low carbon energy planning, where DEMATEL is applied to analyze the degree of interrelationships among each criterion, while ANP can be used to obtain each criterion's weight. The final ranking of each alternative for a low carbon energy plan can be obtained through VIKOR. The detailed steps and explanations for both stages are summarized in the later parts.

\subsection{Procedure of DANP Method}

ANP is an expansion of AHP, which was advanced by Saaty to address the interdependence and feedback between each standard and alternative among real-world problems [41,42]. However, the normalization method for the hyper-matrices is unreasonable because every bunch from the distribution of each norm in the column has the same weight in the customizable course [30]. Therefore, DEMATEL is utilized to better the normalization process in ANP, called DANP. It has been favorably applied in many domains, such as supplier selection and material selection [41-45]. The program is generalized as follows:

Step 1: Count the direct-relation array. The degree to which the standard $i$ has a direct influence on the standard $j$, (denoted by $d_{i j}$ ) may be formed by several specialists/engineers in this domain based on the supposed scales. The direct-relation matrix $A=\left[a_{i j}\right]_{n \times n}$ is then generated by averaging each of the same criteria in all kinds of matrices of specialists/engineers.

Step 2: Set up the primary direct-relation matrix. The primary direct-relation matrix $D=\left[d_{i j}\right]_{n \times n}$ can be derived from normalizing the matrix $A$, as shown in Equations (1) and (2).

$$
\begin{gathered}
D=s \times A \\
s=\min \left[\frac{1}{\max _{i} \sum_{j=1}^{n}\left|a_{i j}\right|}, \frac{1}{\max _{j} \sum_{i=1}^{n}\left|a_{i j}\right|}\right]
\end{gathered}
$$

Step 3: Export the overall direct-relation matrix. Along the powers of $D$, e.g., $D^{2}, D^{3}, \ldots, D^{\alpha}$, the oblique effect of every standard is declining continuously. When $\alpha$ reaches infinity, $D^{\alpha}=[0]_{n \times n^{\prime}}$ where $0 \leq d_{i j}<1,0<\sum_{i} d_{i j} \leq 1$ and $0<\sum_{j} d_{i j} \leq 1$ and at least one column sum $\sum_{i} d_{i j}$ or one row sum $\sum_{j} d_{i j}$ amounts to 1 . Then, the overall direct-relation matrix $T=\left[t_{i j}\right]_{n \times n}$ can be received by Equation (3).

$$
T=D^{1}+D^{2}+\ldots+D^{\alpha}=D(I-D)(I-D)^{-1}=(I-D)^{-1}
$$

where $\lim _{\alpha \rightarrow \infty} D^{\alpha}=[0]_{n \times n}$.

Step 4: Analysis of results. Each row sum vector $r$ and column sum vector $s$ of total direct-relation matrix $T$ are respectively generated by Equations (4) and (5), where $r_{i}$ represents the total effect of the standard $i$ on the other criteria. Likewise, $c_{j}$ expresses the sum of the total effects received by the standard $j$ from other standards. Furthermore, $\left(r_{i}+c_{i}\right)$ and $\left(r_{i}-c_{i}\right)$ should be computed in order to analyze the results. $\left(r_{i}+c_{i}\right)$, as an indicator, can instruct the extent of the core role that standard $i$ plays in the question when $i=j$. On $\left(r_{i}-c_{i}\right)$, if it's positive, the standard $i$ is affecting other criteria; in contrast, other criteria are affecting $i$.

$$
\begin{gathered}
r=\left(r_{i}\right)_{n \times 1}=\left[\sum_{j=1}^{n} t_{i j}\right]_{n \times 1} \\
c=\left(c_{j}\right)_{n \times 1}=\left(c_{j}\right)_{1 \times n}^{\prime}=\left[\sum_{i=1}^{n} t_{i j}\right]_{1 \times n}^{\prime}
\end{gathered}
$$


Step 5: Create a causality graph. By means of a data set of maps $\left(r_{i}+c_{i}, r_{i}-c_{i}\right)$, a causal graph can be constructed to offer an means of ensuring the preferred values in each dimension/cluster and standard are refined.

Step 6: Count the unweighted hypermatrix. Then from DEMATEL, we get two different total direct-relation matrices, i.e., $T_{C}=\left[t_{C}^{i j}\right]_{n \times n}$ being part of $n$ criteria, and $T_{D}=\left[t_{D}^{i j}\right]_{m \times m}$ being specifically for $m$ dimensions/clusters from $T_{C}$, as presented in Equation (6).

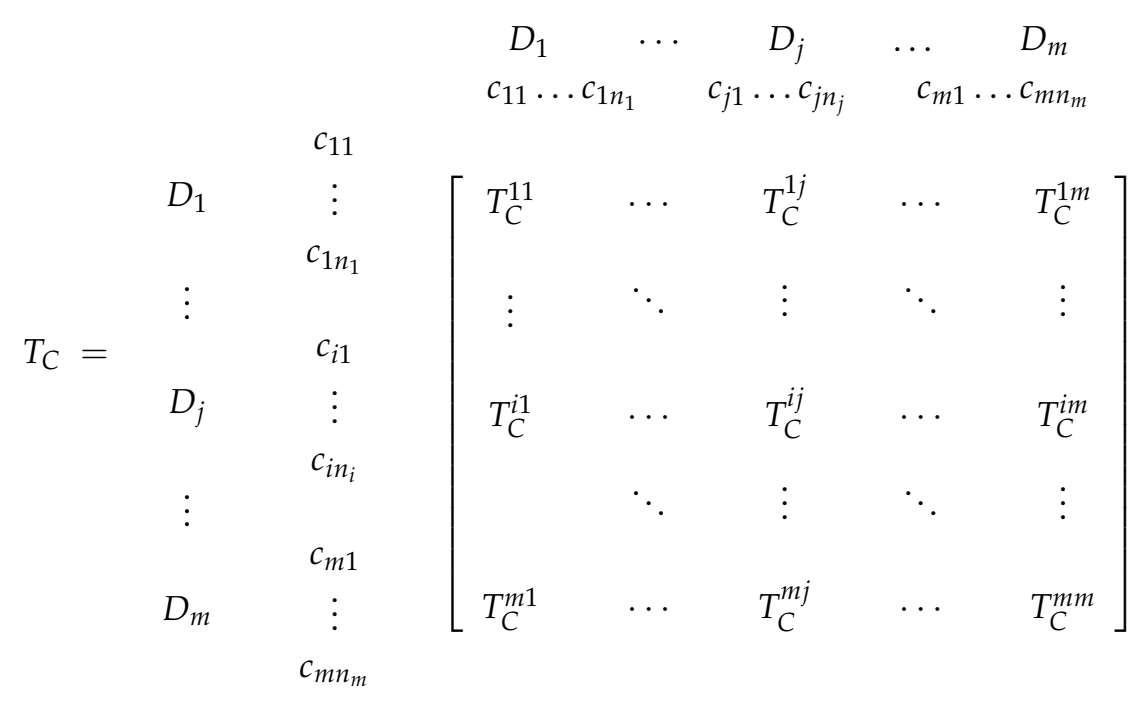

A new matrix $T_{C}^{\delta}$ will be framed through the normalization of the direct relationship array $T_{C}$, as presented in Equations (7) and (8).

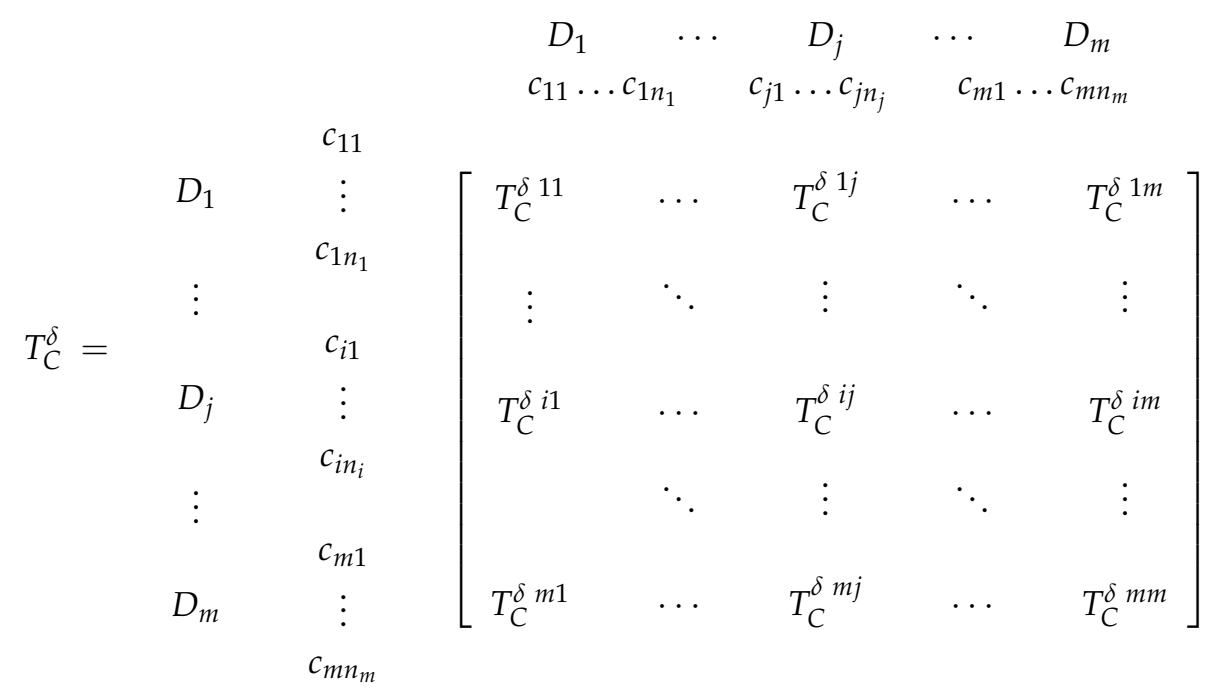

The concrete manifestation of normalization $T_{C}^{\delta 11}$ is presented in Equations (8) and (9). Analogously, other $T_{C}^{\delta}{ }^{i j}$ values can be acquired identically.

$$
T_{C}^{\delta 11}=\left[t_{c i j}^{\delta 11}\right]_{m_{1} \times m_{1}}=\left[\begin{array}{ccccc}
t_{c 11}^{11} / d_{c 1}^{11} & \cdots & t_{c 1 j}^{11} / d_{c 1}^{11} & \cdots & t_{c 1 m_{1}}^{11} / d_{c 1}^{11} \\
\vdots & \ddots & \vdots & \ddots & \vdots \\
t_{c i 1}^{11} / d_{c i}^{11} & \cdots & t_{c i j}^{11} / d_{c i}^{11} & \cdots & t_{c i m_{1}}^{11} / d_{c i}^{11} \\
\vdots & \ddots & \vdots & \ddots & \vdots \\
t_{c m_{1} 1}^{11} / d_{c m_{1}}^{11} & \cdots & t_{c m_{1} j}^{11} / d_{c m_{1}}^{11} & \cdots & t_{c m_{1} m_{1}}^{11} / d_{c m_{1}}^{11}
\end{array}\right]
$$




$$
d_{c i}^{11}=\sum_{j=1}^{m_{1}} t_{i j}^{11}, i=1,2, \ldots, m_{1}
$$

Allow the total direct-relation matrix to match and fill into the interdependence clusters. The unweighted hypermatrix $W$ can be acquired on the foundation by transposing the normalized total direct-relation matrix $T_{c}^{\delta}$, as shown in Equation (10).

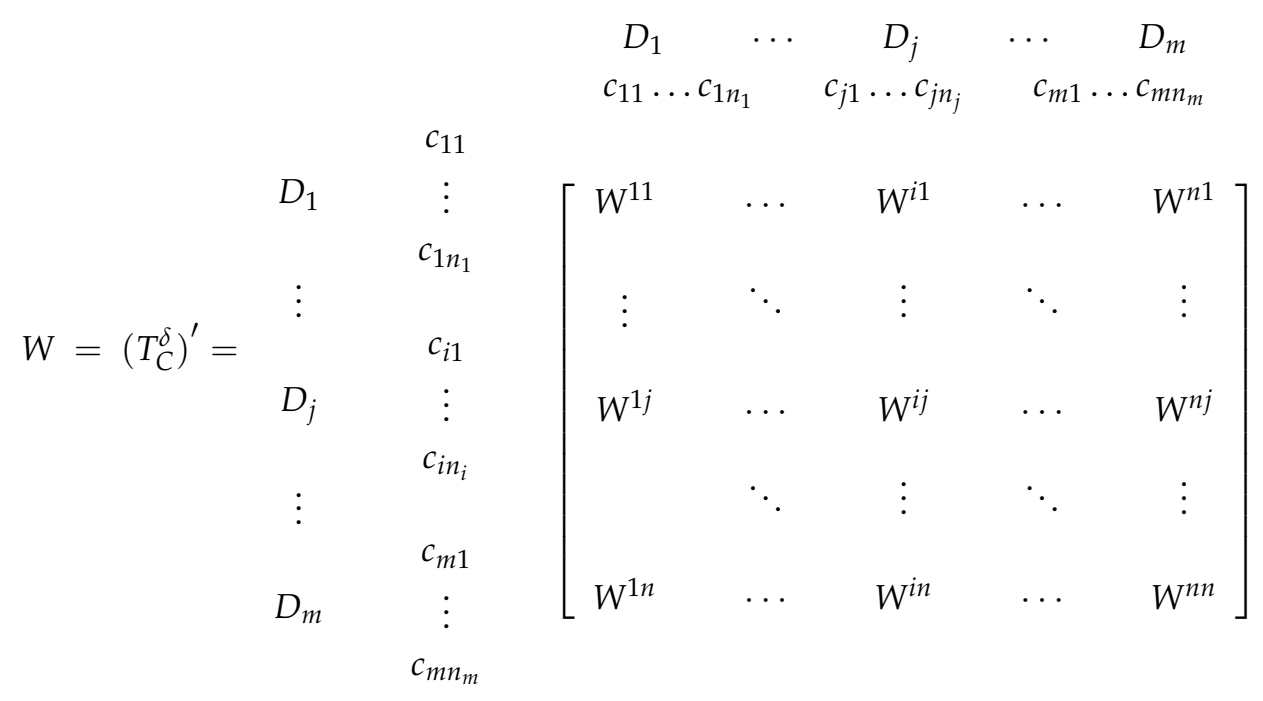

The interpretation for $W^{11}$ is shown as Equation (11). Likewise, other $W^{i j}$ values can be acquired in the same way.

$$
W^{11}=\begin{array}{ccccc}
c_{11} & \cdots & c_{1 i} & \cdots & c_{1 m_{1}} \\
c_{11} \\
\vdots \\
c_{1 j} \\
\vdots \\
c_{1 m_{1}}
\end{array}\left[\begin{array}{ccccc}
t_{c 11}^{\delta 11} & \cdots & t_{c i 1}^{\delta 11} & \cdots & t_{c m_{1} 1}^{\delta 11} \\
\vdots & \ddots & \vdots & \ddots & \vdots \\
t_{c 1 j}^{\delta 11} & \cdots & t_{c i j}^{\delta 11} & \cdots & t_{c m_{1} j}^{\delta 11} \\
\vdots & \ddots & \vdots & \ddots & \vdots \\
t_{c 1 m_{1}}^{\delta 11} & \cdots & t_{c i m_{1}}^{\delta 11} & \cdots & t_{c m_{1} m_{1}}^{\delta 11}
\end{array}\right]
$$

Step 7: Calculate the weighted supermatrix. Each column will be summed for normalization as Equation (12).

The weighted hyper-matrices are counted. The sum of each column is normalized.

$$
T_{D}=\left[\begin{array}{ccccc}
t_{D}^{11} & \cdots & t_{D}^{1 j} & \cdots & t_{D}^{1 n} \\
\vdots & \ddots & \vdots & \ddots & \vdots \\
t_{D}^{11} & \cdots & t_{D}^{i j} & \cdots & t_{D}^{i n} \\
\vdots & \ddots & \vdots & \ddots & \vdots \\
t_{D}^{n 1} & \cdots & t_{D}^{n j} & \cdots & t_{D}^{n n}
\end{array}\right]
$$

Create a new matrix $T_{D}^{\delta}$ by normalizing the total direct-relation matrix $T_{D}$, as shown in Equation (13).

$$
T_{D}^{\delta}=\left[t_{D}^{\delta i j}\right]=\left[\begin{array}{ccccc}
t_{D}^{11} / d_{1} & \cdots & t_{D}^{1 j} / d_{1} & \cdots & t_{D}^{1 n} / d_{1} \\
\vdots & \ddots & \vdots & \ddots & \vdots \\
t_{D}^{i 1} / d_{i} & \cdots & t_{D}^{i j} / d_{i} & \cdots & t_{D}^{i n} / d_{i} \\
\vdots & \ddots & \vdots & \ddots & \vdots \\
t_{D}^{n 1} / d_{n} & \cdots & t_{D}^{n j} / d_{n} & \cdots & t_{D}^{n n} / d_{n}
\end{array}\right]
$$


In order to get the weighted hyper-matrix, it is necessary to multiply the normalized total direct-relation matrix $T_{D}^{\delta}$, as shown in Equation (14).

$$
W^{\delta}=T_{D}^{\delta} \times W=\left[\begin{array}{ccccc}
t_{D}^{\delta 11} \times W^{11} & \cdots & t_{D}^{\delta i 1} \times W^{i 1} & \cdots & t_{D}^{\delta n 1} \times W^{n 1} \\
\vdots & \ddots & \vdots & \ddots & \vdots \\
t_{D}^{\delta 1 j} \times W^{1 j} & \cdots & t_{D}^{\delta i j} \times W^{i j} & \cdots & t_{D}^{\delta n j} \times W^{n j} \\
\vdots & \ddots & \vdots & \ddots & \vdots \\
t_{D}^{\delta 1 n} \times W^{1 n} & \cdots & t_{D}^{\delta i n} \times W^{i n} & \cdots & t_{D}^{\delta n n} \times W^{n n}
\end{array}\right]
$$

Step 8: Restrict the weighted supermatrix.

\subsection{Steps of VIKOR Method}

In order to optimize the multi-criteria of intricate systems, Opricovic used the VIKOR method in 1998 [46,47]. VIKOR is used to rank and sort a group of alternative schemes based on a variety of possible conflicting and noncomparable criteria, supposing that such a compromise can handle collisions. It adopts the multi-criteria ranking exponent in view of the specific measure of 'closeness' to the 'ideal' solution [48].

For the $J$ alternatives, each scheme is represented by $A_{1}, A_{2}, \ldots, A_{J}$, respectively, and is measured according to the $i$-th criteria $C_{i}$. The result of the measurement is represented by $f_{i j}$. The VIKOR method was exploited with the pattern of $L_{p}$-metric, described as follows:

$$
L_{p, j}=\left\{\sum_{i=1}^{n}\left[w_{i}\left(f_{i}^{*}-f_{i j}\right) /\left(f_{i}^{*}-f_{i}^{-}\right)\right]^{p}\right\}^{1 / p} \quad 1 \leq p \leq \infty, j=1,2, \ldots, J
$$

The steps of compromise ranking algorithm VIKOR:

Step 1: Compute the normalized decision matrix $B=\left[a_{i j}\right]$.

For the benefit virtue or element, count the normalized value $y_{i j}$,

$$
b_{i j}=\frac{a_{i j}}{\max _{i} a_{i j}},(i=1,2, \ldots, n ; j=1,2, \ldots, m)
$$

For the cost virtue or element, the normalized value $y_{i j}$ is counted as

$$
b_{i j}=\frac{\min _{i} a_{i j}}{a_{i j}},(i=1,2, \ldots, n ; j=1,2, \ldots, m)
$$

Step 2: Calculate the normalized decision matrix $Z$ using weights vector.

$$
Z=\omega^{T} B
$$

Step 3: Define the optimum $f_{i}^{*}$ and the worst $f_{i}^{-}$values of entire criterion functions, $i=1,2, \ldots, n$.

$$
\begin{aligned}
& f_{i}^{*}=\left[\left(\max _{j} z_{i j} \mid i \in C\right),\left(\min _{j} z_{i j} \mid i \in D\right)\right], \forall i \\
& f_{i}^{-}=\left[\left(\min _{j} z_{i j} \mid i \in C\right),\left(\max _{j} z_{i j} \mid i \in D\right)\right], \forall i
\end{aligned}
$$

$C$ represents benefit collection, and $D$ represents cost collection.

Step 4: Count the value of $S_{j}$ and $R_{j} ; j=1,2, \ldots, m$, using the relations

$$
S_{j}=\sum_{i=1}^{n} w_{i} \frac{\left(f_{i}^{*}-f_{i j}\right)}{\left(f_{i}^{*}-f_{i}^{-}\right)}, \forall j
$$




$$
R_{j}=\max _{i}\left[w_{i} \frac{\left(f_{i}^{*}-f_{i j}\right)}{\left(f_{i}^{*}-f_{i}^{-}\right)}\right], \forall j
$$

The weights criteria $\left(w_{i}\right)$ indicate the relative significance between them.

Step 5: Count the value of $Q_{j}, j=1,2, \ldots, m$, using the relation.

$$
Q_{j}=v \frac{\left(S_{j}-S^{*}\right)}{\left(S^{-}-S^{*}\right)}+(1-v) \frac{\left(R_{j}-R^{*}\right)}{\left(R^{-}-R^{*}\right)}, \forall j
$$

and then,

$$
\begin{gathered}
S^{*}=\min S_{j}, S^{-}=\max S_{j} \\
R^{*}=\min R_{j}, R^{-}=\max R_{j}
\end{gathered}
$$

$v$ is used for the weight of the tactics of "the majority of criteria", here $v=0.5$.

Step 6: estimating criteria:

C1: $Q_{j}^{\prime \prime}-Q_{j}^{\prime} \geq 1 /(j-1)$ where, $Q_{j}^{\prime \prime}$ and $Q_{j}^{\prime}$ are the first and second choice, separately. $J$ is the number of alternate solutions.

C2: Sort the first solution $S_{j}$ (or $R_{j}$ ) in $Q_{j}$ value; then sort the second at the same time.

\section{Case Study}

\subsection{Data Collection}

In this section, the quality of the four design alternatives for low-carbon energy planning from a certain province in China is appraised using the proposed model in practical case [49]. An overall description, including the 13 criteria of the four design alternatives, is presented in Table 1 . A questionnaire was used to gather initial data and related information about each design alternative from specialists with expertise and administrative experience, particularly those with knowledge of the low-carbon economy in China. The group of experts is depicted below: business executives who are adept in energy system analysis; academicians are those who major in energy system planning and participate in university-related teaching. The 12 experts that have been investigated included four scholars committed to energy systems, four supervisors coming from energy enterprises with professional skills, and four electric power staffs who have engaged in their occupations for over five years. The survey was conducted in November 2016; each person was asked to conduct a 60-35 min questionnaire and interview. The main contents of our designed questionnaires concerned cost, safety, reliability, and environmental protection, as shown in the first column of Table 1 . The initial data gathered through interviews is presented in the rest of Table 1. The inconsistency rate of these questionnaires was $4.5 \%$, which signifies that extra questionnaires in this study will not affect the results, and that the credibility rating is $95.50 \%$.

Figure 2 presents a clear overall diagram of the adopted methodology, from the beginning, i.e., determining each criterion of low carbon energy planning evaluation, the second phase, i.e., calculating the normalized decision matrix, to the final step, i.e., ranking the alternatives of low-carbon energy planning. 


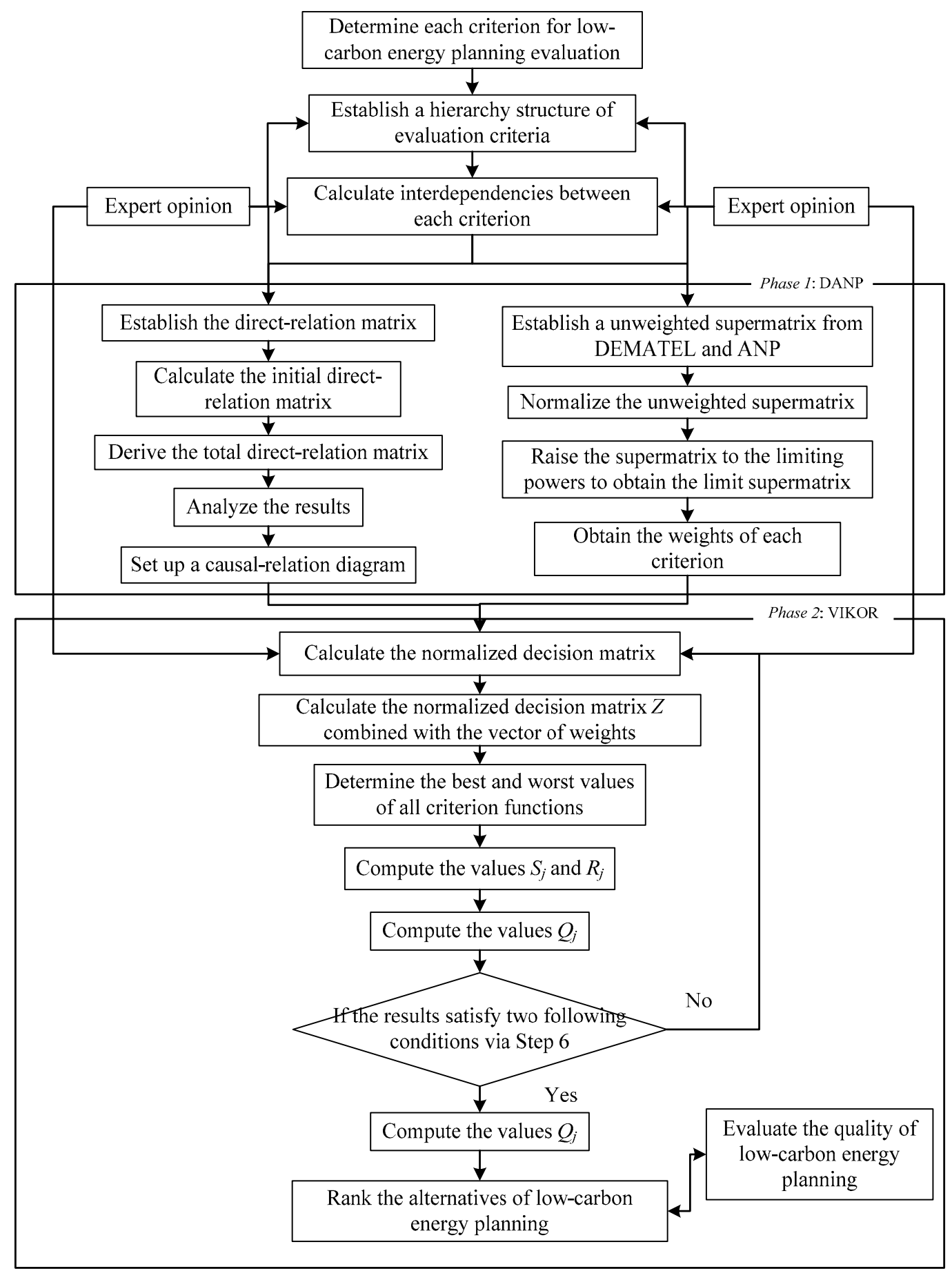

Figure 2. Methodology flowchart.

\subsection{Weighing Relation between Dimensions and Criteria by DEMATEL}

Here, we apply the DEMATEL decision-making framework to perform the four dimensions using 15 criteria and their interrelationships. Based on the questionnaires from 12 specialists, the degree of influence of the relationships between the dimensions and criteria can be determined, as shown in Table 2. The detailed procedure can be summarized: (1) Count the original direct-relation array by Equations (1) and (2); (2) The total direct-relation array is acquired via Equation (3); (3) Each row sum vector $r$ and column sum vector $s$ of overall direct-relation matrix $T$ is generated as listed in Equations (4) and (5) respectively, and the results are listed in Tables 3 and 4; (4) A causal influence diagram is set up based on the $r_{i}+c_{i}$ and $r_{i}-c_{i}$ values respectively and Table 5 shows the sum of 
influences given and received on dimensions. The causal influence diagrams of criteria and dimensions are listed in Figure 3.

Table 1. The initial data for alternatives corresponding to each criterion. (Zhong et al., 2015).

\begin{tabular}{ccccc}
\hline Criteria & Alternative 1 & Alternative 2 & Alternative 3 & Alternative 4 \\
\hline Power shortage expectations $\left(C_{1}\right)$ & 4.19 & 14.2 & 3.16 & 8.67 \\
Power shortage frequency $\left(C_{2}\right)$ & 16,801 & 17,558 & 704 & 8019 \\
Duration of power shortage $\left(C_{3}\right)$ & 2.45 & 3.92 & 2.45 & 4.14 \\
Low battery expectations $\left(C_{4}\right)$ & 87.67 & 82.47 & 1.95 & 49.27 \\
Power load matching degree $\left(C_{5}\right)$ & 1.26 & 1.46 & 1.62 & 1.81 \\
The proportion of intermittent energy $\left(C_{6}\right)$ & 1.872 & 0.107 & 1.431 & 0.294 \\
Positive peaking capacity $\left(C_{7}\right)$ & -14.34 & 0.536 & -3.705 & 26.481 \\
The proportion of outside electricity $\left(C_{8}\right)$ & 11.075 & 3.643 & 2.522 & -34.229 \\
Investment costs $\left(C_{9}\right)$ & 2897.27 & 1872.89 & 2461.87 & 2134.69 \\
Operating costs $\left(C_{10}\right)$ & 835.06 & 449.54 & 629.51 & 543.79 \\
Plant electricity rate $\left(C_{11}\right)$ & 5.44 & 6.40 & 7.43 & 8.02 \\
Carbon emissions costs $\left(C_{12}\right)$ & 256.05 & 120.51 & 203.02 & 194.38 \\
Proportion of renewable energy $\left(C_{13}\right)$ & 7.41 & 7.91 & 3.17 & 4.23 \\
CO ${ }_{2}$ emissions $\left(C_{14}\right)$ & $35,006.94$ & $20,511.42$ & $29,212.80$ & $24,757.93$ \\
Nitrogen oxide emissions $\left(C_{15}\right)$ & 254.42 & 149.07 & 212.31 & 179.94 \\
\hline
\end{tabular}

Table 2. The averaged direct-relation matrix for criteria.

\begin{tabular}{cccccccccccccccc}
\hline & $\mathrm{C}_{\mathbf{1}}$ & $\mathrm{C}_{\mathbf{2}}$ & $\mathrm{C}_{\mathbf{3}}$ & $\mathrm{C}_{\mathbf{4}}$ & $\mathrm{C}_{\mathbf{5}}$ & $\mathrm{C}_{\mathbf{6}}$ & $\mathrm{C}_{\mathbf{7}}$ & $\mathrm{C}_{\mathbf{8}}$ & $\mathrm{C}_{\mathbf{9}}$ & $\mathrm{C}_{\mathbf{1 0}}$ & $\mathrm{C}_{\mathbf{1 1}}$ & $\mathrm{C}_{\mathbf{1 2}}$ & $\mathrm{C}_{\mathbf{1 3}}$ & $\mathrm{C}_{\mathbf{1 4}}$ & $\mathrm{C}_{\mathbf{1 5}}$ \\
\hline $\mathrm{C}_{1}$ & 0 & 1 & 1 & 2 & 1 & 3 & 1 & 2 & 1 & 1 & 1 & 1 & 1 & 1 & 3 \\
$\mathrm{C}_{2}$ & 1 & 0 & 1 & 2 & 1 & 1 & 1 & 1 & 1 & 2 & 1 & 1 & 1 & 1 & 1 \\
$\mathrm{C}_{3}$ & 1 & 1 & 0 & 1 & 1 & 1 & 1 & 2 & 1 & 1 & 1 & 1 & 1 & 1 & 2 \\
$\mathrm{C}_{4}$ & 1 & 2 & 1 & 0 & 1 & 1 & 2 & 1 & 1 & 3 & 1 & 2 & 4 & 1 & 1 \\
$\mathrm{C}_{5}$ & 1 & 1 & 1 & 1 & 0 & 1 & 1 & 2 & 1 & 1 & 2 & 1 & 2 & 1 & 1 \\
$\mathrm{C}_{6}$ & 1 & 2 & 2 & 2 & 1 & 0 & 2 & 3 & 2 & 1 & 1 & 1 & 2 & 3 & 2 \\
$\mathrm{C}_{7}$ & 2 & 1 & 3 & 2 & 2 & 1 & 0 & 3 & 4 & 1 & 2 & 1 & 3 & 3 & 2 \\
$\mathrm{C}_{8}$ & 3 & 1 & 2 & 1 & 1 & 1 & 2 & 0 & 3 & 1 & 1 & 2 & 3 & 2 & 2 \\
$\mathrm{C}_{9}$ & 2 & 3 & 1 & 2 & 2 & 3 & 2 & 1 & 0 & 1 & 1 & 2 & 2 & 1 & 4 \\
$\mathrm{C}_{10}$ & 1 & 1 & 1 & 1 & 3 & 1 & 2 & 2 & 2 & 0 & 1 & 2 & 3 & 2 & 3 \\
$\mathrm{C}_{11}$ & 2 & 1 & 2 & 1 & 2 & 1 & 1 & 2 & 1 & 1 & 0 & 2 & 1 & 2 & 2 \\
$\mathrm{C}_{12}$ & 1 & 2 & 1 & 1 & 2 & 2 & 3 & 2 & 1 & 2 & 1 & 0 & 1 & 1 & 2 \\
$\mathrm{C}_{13}$ & 1 & 3 & 1 & 1 & 1 & 1 & 1 & 2 & 1 & 1 & 2 & 2 & 0 & 2 & 1 \\
$\mathrm{C}_{14}$ & 2 & 1 & 2 & 3 & 1 & 2 & 1 & 1 & 2 & 1 & 3 & 2 & 2 & 0 & 1 \\
$\mathrm{C}_{15}$ & 2 & 1 & 1 & 1 & 2 & 3 & 2 & 1 & 2 & 3 & 2 & 1 & 1 & 2 & 0 \\
\hline
\end{tabular}

Table 3. The averaged direct-relation matrix for dimensions.

\begin{tabular}{ccccc}
\hline & $\mathrm{E}_{\mathbf{1}}$ & $\mathrm{E}_{\mathbf{2}}$ & $\mathrm{E}_{\mathbf{3}}$ & $\mathrm{E}_{\mathbf{4}}$ \\
\hline $\mathrm{E}_{1}$ & 0 & 2 & 3 & 1 \\
$\mathrm{E}_{2}$ & 2 & 0 & 3 & 2 \\
$\mathrm{E}_{3}$ & 1 & 1 & 0 & 2 \\
$\mathrm{E}_{4}$ & 3 & 2 & 2 & 0 \\
\hline
\end{tabular}

Table 4. Sum of influences given and received on criteria.

\begin{tabular}{cccccc}
\hline & Criteria & $r_{\boldsymbol{i}}$ & $c_{\boldsymbol{i}}$ & $\boldsymbol{r}_{\boldsymbol{i}}+\boldsymbol{c}_{\boldsymbol{i}}$ & $\boldsymbol{r}_{\boldsymbol{i}}-\boldsymbol{c}_{\boldsymbol{i}}$ \\
\hline 1 & Power shortage expectations $\left(C_{1}\right)$ & 2.784 & 2.673 & 5.457 & 0.111 \\
2 & Power shortage frequency $\left(C_{2}\right)$ & 2.782 & 2.126 & 4.908 & 0.656 \\
3 & Duration of power shortage $\left(C_{3}\right)$ & 2.625 & 2.137 & 4.762 & 0.488 \\
4 & Low battery expectations $\left(C_{4}\right)$ & 2.749 & 2.871 & 5.620 & -0.122 \\
5 & Power load matching degree $\left(C_{5}\right)$ & 2.737 & 2.237 & 4.974 & 0.500 \\
\hline
\end{tabular}


Table 4. Cont

\begin{tabular}{cccccc}
\hline & Criteria & $r_{i}$ & $c_{i}$ & $r_{i}+c_{i}$ & $r_{i}-c_{i}$ \\
\hline 6 & The proportion of intermittent energy $\left(C_{6}\right)$ & 3.284 & 2.908 & 6.192 & 0.376 \\
7 & Positive peaking capacity $\left(C_{7}\right)$ & 2.881 & 3.876 & 6.757 & -0.995 \\
8 & The proportion of outside electricity $\left(C_{8}\right)$ & 3.275 & 3.227 & 6.502 & 0.048 \\
9 & Investment costs $\left(C_{9}\right)$ & 3.030 & 3.495 & 6.525 & -0.465 \\
10 & Operating costs $\left(C_{10}\right)$ & 3.273 & 2.638 & 5.911 & 0.635 \\
11 & Plant electricity rate $\left(C_{11}\right)$ & 2.659 & 2.720 & 5.379 & -0.061 \\
12 & Carbon emissions costs $\left(C_{12}\right)$ & 2.933 & 2.761 & 5.694 & 0.172 \\
13 & Proportion of renewable energy $\left(C_{13}\right)$ & 3.491 & 2.582 & 6.073 & 0.909 \\
14 & $\mathrm{CO}_{2}$ emissions $\left(C_{14}\right)$ & 3.027 & 3.099 & 6.126 & -0.072 \\
15 & Nitrogen oxide emissions $\left(C_{15}\right)$ & 3.476 & 3.193 & 6.669 & 0.283 \\
\hline
\end{tabular}

Table 5. Sum of influences given and received on dimensions.

\begin{tabular}{cccccc}
\hline & Criteria & $\boldsymbol{r}_{\boldsymbol{i}}$ & $\boldsymbol{c}_{\boldsymbol{i}}$ & $\boldsymbol{r}_{\boldsymbol{i}}+\boldsymbol{c}_{\boldsymbol{i}}$ & $\boldsymbol{r}_{\boldsymbol{i}}-\boldsymbol{c}_{\boldsymbol{i}}$ \\
\hline $\mathbf{1}$ & Reliability property $\left(E_{1}\right)$ & 2.672 & 2.664 & 5.336 & 0.008 \\
$\mathbf{2}$ & Safety property $\left(E_{2}\right)$ & 2.331 & 3.079 & 5.410 & -0.748 \\
$\mathbf{3}$ & Economy property $\left(E_{3}\right)$ & 3.479 & 2.004 & 5.483 & 1.475 \\
$\mathbf{4}$ & Environmental property $\left(E_{4}\right)$ & 2.411 & 3.145 & 5.556 & -0.734 \\
\hline
\end{tabular}

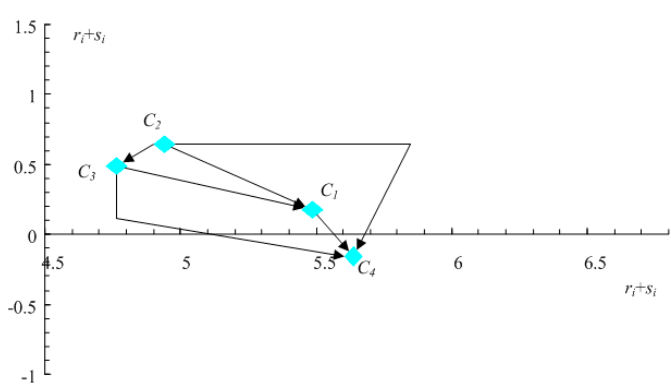

(a) Causal influence diagrams of $\mathrm{C} 1, \mathrm{C} 2, \mathrm{C} 3, \mathrm{C} 4$

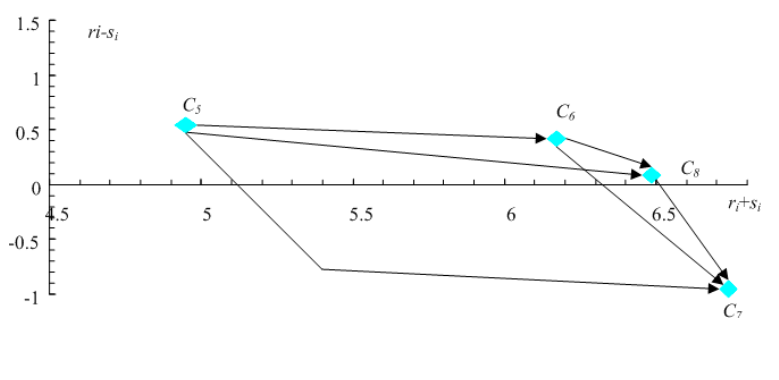

(b) Casual influence diagrams of C5, C6, C7, C8

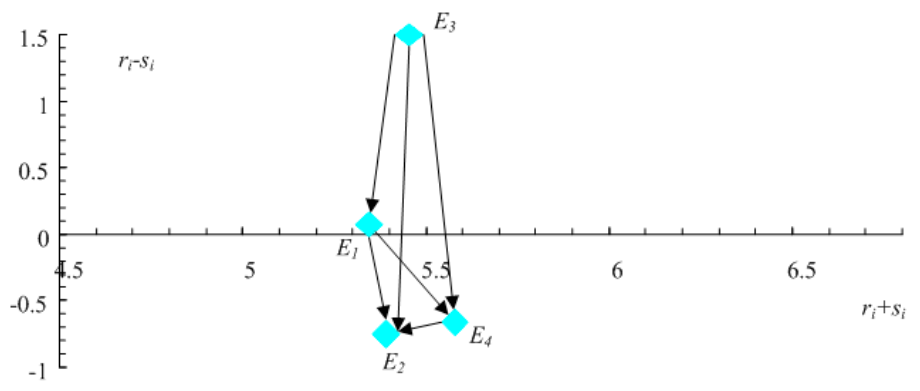

(c) Casual influence diagrams of E1, E2, E3, E4

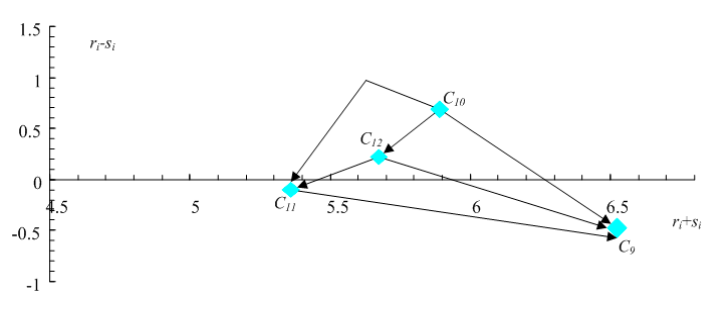

(d) Casual influence diagrams of C9, C10, C11, C12

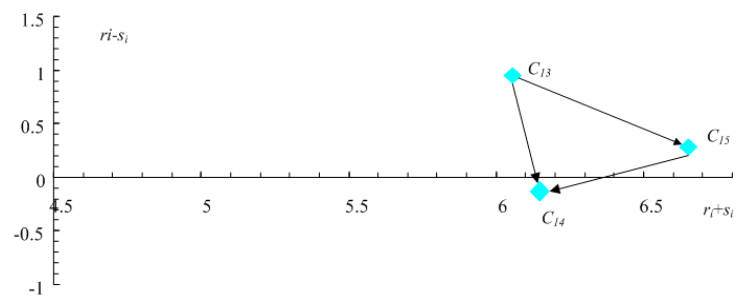

(e) Casual influence diagrams of C13, C14, C15

Figure 3. Causal influence diagram for dimensions and criteria. 
The subfigure (a) of Figure 3 shows the causal influence diagrams of C1, C2, C3, C4. (b), (d) and (e) show the casual influence diagrams of $\mathrm{C} 5, \mathrm{C} 6, \mathrm{C} 7, \mathrm{C} 8$ and $\mathrm{C} 9, \mathrm{C} 10, \mathrm{C} 11, \mathrm{C} 12$ and $\mathrm{C} 13, \mathrm{C} 14, \mathrm{C} 15$, respectively. The subfigure (e) shows the casual influence diagrams of E1, E2, E3, E4.

\subsection{Weighting of Every Standard by DANP Technique}

In this part, we applied the DANP approach that links DEMATEL with ANP to determine the weights of every element. The detailed process can be divided into three parts, as follows: (1) Unweighted supermatrix is developed through Equations (6)-(11); (2) A weighted supermatrix is based on Equations (12)-(14); (3) Limit the weighted supermatrix; the complete list is shown in Table 6.

Table 6. The weights of each criterion.

\begin{tabular}{cccccccccccccccc}
\hline Criteria & $\mathrm{C}_{\mathbf{1}}$ & $\mathrm{C}_{\mathbf{2}}$ & $\mathrm{C}_{\mathbf{3}}$ & $\mathrm{C}_{\mathbf{4}}$ & $\mathrm{C}_{\mathbf{5}}$ & $\mathrm{C}_{\mathbf{6}}$ & $\mathrm{C}_{\mathbf{7}}$ & $\mathrm{C}_{\mathbf{8}}$ & $\mathrm{C}_{\mathbf{9}}$ & $\mathrm{C}_{\mathbf{1 0}}$ & $\mathrm{C}_{\mathbf{1 1}}$ & $\mathrm{C}_{\mathbf{1 2}}$ & $\mathrm{C}_{\mathbf{1 3}}$ & $\mathrm{C}_{\mathbf{1 4}}$ & $\mathrm{C}_{\mathbf{1 5}}$ \\
\hline Weight & 0.059 & 0.065 & 0.030 & 0.071 & 0.082 & 0.094 & 0.099 & 0.027 & 0.097 & 0.085 & 0.020 & 0.081 & 0.070 & 0.095 & 0.025 \\
\hline
\end{tabular}

\subsection{Rank the Design Alternatives of Low-Carbon Energy Planning Using the VIKOR Approach}

Due to the related documents and specialist consultation, the values to each criterion of four design alternatives can be obtained, as shown in Table 1. The procedure of VIKOR is revealed in Section 4.2. Note that the initial matrix $A$ can be formulated according to Table 1 . To obtain the ultimate rank of the design alternatives for low-carbon energy planning, the steps can be decomposed into six sub-steps: (1) Obtain the normalized decision matrix $B$ via Equations (16) and (17); (2) the normalized decision matrix $Z$ using the vector of weights can be calculated by Equation (18); (3) Give the best $f_{i}^{*}$ and the worst $f_{i}^{-}$values of all criterion functions, as shown in Equations (19) and (20); (4) The values $S_{j}$ and $R_{j}$ can be obtained in Equations (21) and (22) (as shown in Table 7); (5) The values $Q_{j}$ can be computed based on the values $S_{j}$ and $R_{j}$ via Eqution (23) (as shown in Table 7); (6) Judging criteria as $\mathrm{C} 1$ and $\mathrm{C} 2$. If the results satisfy the two following conditions via Step 6 in Section 3.2, rank the design alternatives of low-carbon energy planning based on the values $Q_{j}$.

Table 7. The values of $S_{j}, R_{j}$ and $Q_{j}$.

\begin{tabular}{ccccccc}
\hline & $S_{j}$ & Rank & $\boldsymbol{R}_{\boldsymbol{j}}$ & Rank & $\boldsymbol{Q}_{j}$ & Rank \\
\hline Alternative 1 & 0.568 & 3 & 0.182 & 4 & 0.527 & 3 \\
Alternative 2 & 0.845 & 4 & 0.180 & 3 & 0.850 & 4 \\
Alternative 3 & 0.294 & 2 & 0.075 & 2 & 0.113 & 2 \\
Alternative 4 & 0.204 & 1 & 0.064 & 1 & 0.086 & 1 \\
\hline
\end{tabular}

\section{Analysis and Discussion}

\subsection{Comparison with Previous Methods}

To verify the feasibility and validity of this hybrid method, TOPSIS and GRA methods are displayed as the object of comparison. (The process of these two methods is shown in [50]). The identical weight of every standard is employed in three ways. The result is presented on the basis of the same case. On account of the original data, as shown in Table 7, the closeness indices of three methodologies, i.e., VIKOR, GRA, and TOPSIS, can be seen in Table 8.

Table 8. The results of the three methods.

\begin{tabular}{ccccccc}
\hline & VIKOR & Rank & GRA & Rank & TOPSIS & Rank \\
\hline Alternative 1 & 0.527 & 3 & 0.390 & 3 & 0.445 & 4 \\
Alternative 2 & 0.850 & 4 & 0.252 & 4 & 0.458 & 3 \\
Alternative 3 & 0.113 & 2 & 0.548 & 2 & 0.748 & 2 \\
Alternative 4 & 0.086 & 1 & 0.716 & 1 & 0.854 & 1 \\
\hline
\end{tabular}


As can be seen from Table 8, the results of these three methods are basically the same. This means that the proposed method is effective at ranking the design alternatives and evaluating the quality of low-carbon energy planning. Regarding VIKOR result, alternative 4 ranks the first with a value of 0.086. It is the same case as the GRA ranking result, where alternative 4 comes first with a score of 0.716. The TOPSIS result reveals a slight ranking variation of alternative 1 and Alternative 2 compared to the VIKOR and GRA, but alternative 4 still ranks first. Subsequently, through the results of the three methodologies, alternative 4 for low-carbon energy planning is optimal.

\subsection{Discussion}

As shown in the case study for four design alternatives in Section 5, the hybrid MCDM approach, i.e., DANP-VIKOR, could offer more related outcomes, such as the interdependent and feedback of dimensions and criteria. According to the procedure of DANP and VIKOR, several conclusions can be summarized: (1) Through the results of the DEMENTAL approach, we observe that the four dimensions interact with each other, e.g., reliability property $\left(E_{1}\right)$ will influence safety property $\left(E_{2}\right)$, economy property $\left(E_{3}\right)$ and environmental property $\left(E_{4}\right)$. (2) According to the procedure of DANP, the final weights of each criterion can be calculated, and it can be seen that positive peaking capacity $\left(C_{7}\right)$, investment costs $\left(C_{9}\right), \mathrm{CO}_{2}$ emissions $\left(C_{14}\right)$, and the proportion of intermittent energy $\left(C_{6}\right)$ have a large impact on low-carbon energy planning. Therefore, their proper control can lead to better designs for low-carbon energy planning engineers/designers. (3) The influence degree of each dimension and criterion can be obtained from DEMENTAL, as shown in Figure 3. (4) The final rank of the four design alternatives for low-carbon energy planning can be calculated via VIKOR. Based on our comparison with previous methods, i.e., GRA and TOPSIS, it can be concluded that this evaluation method is reasonable and effective.

\section{Conclusions}

Nowadays, resource shortages and environmental pollution are causing great concern, and sustainable development as one of the emerging strategies to address these issues has been much studied, especially in developing countries. Low-carbon energy planning, as one of the essential strategies to sustainable development, can effectively save energy and protect the environment. In summary, the following outcomes are achieved in this paper: (1) A suitable hierarchy structure for each criterion involving cost, safety, reliability, and environmental protection is proposed for low-carbon planning selection. (2) For the first time, the proposed MCDM methodology combining DEMATEL, ANP, and VIKOR is applied to obtain the weight of each criterion, in which the DEMATEL is utilized for normalization processes and to evaluate each alternative for low-carbon energy planning. (3) By comparing the results from TOPSIS and GRA, the effectiveness and feasibility of the hybrid method are validated for assessments of low-carbon energy planning alternatives. In conclusion, the proposed hybrid method is effective for evaluating alternatives for low-carbon energy planning.

As future work, our research will pay attention to three aspects: (1) Based on this research, other crucial factors will be considered, e.g., technical factors, efficiency factors, and so on. (2) The proposed method will be applied in other fields, such as green evaluation and energy saving assessments. Moreover, software related to assessment methods will be designed and applied in the assessment process. (3) For the uncertainty of experts' evaluations, uncertainty theory will be studied in the future $[35,36,51,52]$.

Author Contributions: R.L. and X.Z. conceived and designed the research and prepared the first draft. H.S. and L.Z. supervised the research and analyzed data and results. Y.C. and prepared the data and implemented the method. Q.Z. and L.Z analyzed the data and results and performed editing and revision of the draft.

Funding: This work is supported in part by Science and technology development project of Jilin Province under no. 201801010581C. 
Acknowledgments: In this section you can acknowledge any support given which is not covered by the author contribution or funding sections. This may include administrative and technical support, or donations in kind (e.g., materials used for experiments).

Conflicts of Interest: The authors declare no competing interest.

\section{References}

1. Lang, D.J.; Wiek, A.; Bergmann, M.; Stauffacher, M.; Martens, P.; Moll, P.; Swilling, M.; Thomas, C.J. Transdisciplinary research in sustainability science: Practice, principles, and challenges. Sustain. Sci. 2002, 7, 25-43. [CrossRef]

2. Liu, Z.; Wu, D.; He, B.J.; Liu, Y.; Zhang, X.; Yu, H.; Jin, G. Using solar house to alleviate energy poverty of rural Qinghai-Tibet region, China: A case study of a novel hybrid heating system. Energy Build. 2018, 178, 294-303. [CrossRef]

3. Brundiers, K.; Wiek, A. Educating students in real-world sustainability research: Vision and implementation. Innov. High. Educ. 2011, 36, 107-124. [CrossRef]

4. Tian, G.; Zhang, H.; Feng, Y.; Jia, H.; Zhang, C.; Jiang, Z.; Li, Z.; Li, P. Operation patterns analysis of automotive components remanufacturing industry development in China. J. Clean. Prod. 2017, 164, 1363-1375. [CrossRef]

5. Wu, Z.; Tang, J.; Wang, D. Low carbon urban transitioning in Shenzhen: A multi-level environmental governance perspective. Sustainability 2016, 8, 720. [CrossRef]

6. Abeysundara, U.Y.; Babel, S.; Gheewala, S. A matrix in life cycle perspective for selecting sustainable materials for buildings in Sri Lanka. Build. Environ. 2009, 44, 997-1004. [CrossRef]

7. Singh, S.; Olugu, E.V.; Musa, S.N.; Mahat, A.B.; Wong, K.Y. Strategy selection for sustainable manufacturing with integrated AHP-VIKOR method under interval-valued fuzzy environment. J. Adv. Manuf. Technol. 2016, 84, 547-563. [CrossRef]

8. Ding, L.; Shao, Z.; Zhang, H. A comprehensive evaluation of urban sustainable development in China based on the TOPSIS-entropy method. Sustainability 2016, 8, 746. [CrossRef]

9. Bansal, P. Evolving sustainably: A longitudinal study of corporate sustainable development. Strateg. Manag. J. 2005, 26, 197-218. [CrossRef]

10. Dincer, I. The role of exergy in energy policy making. Energy Policy 2002, 30, 137-149. [CrossRef]

11. Liu, Q.; Chen, Y.; Tian, C. Strategic deliberation on development of low-carbon energy system in China. Adv. Clim. Change Res. 2016, 7, 26-34. [CrossRef]

12. Tsai, B.H.; Chang, C.J.; Chang, C.H. Elucidating the consumption and CO2 emissions of fossil fuels and low-carbon energy in the United States using Lotka-Volterra models. Energy 2016, 100, 416-424. [CrossRef]

13. Liu, Z.; Wu, D.; Yu, H.; Ma, W.; Gin, G. Field measurement and numerical simulation of combined solar heating operation modes for domestic buildings based on the Qinghai-Tibetan plateau case. Energy Build. 2018, 167, 312-321. [CrossRef]

14. Lugaric, L.; Krajcar, S. Transforming cities towards sustainable low-carbon energy systems using emergy synarticle for support in decision making. Energy Policy 2016, 98, 471-482. [CrossRef]

15. Roth, R.; Field, F.; Clark, J. Materials selection and multi-attribute utility analysis. J. Comput. Aided Mater. Des. 1993, 1, 325-342. [CrossRef]

16. Tian, G.; Zhang, H.; Feng, Y.; Wang, D.; Peng, Y.; Jia, H. Green decoration materials selection under interior environment characteristics: A grey-correlation based hybrid MCDM method. Renew. Sustain. Energy Rev. 2018, 81, 682-692. [CrossRef]

17. Rao, R.V.; Davim, J.P. A decision-making framework model for material selection using a combined multiple attribute decision making method. J. Adv. Manuf. Technol. 2008, 35, 751-760. [CrossRef]

18. Shahabi, H.; Hashim, M. Landslide susceptibility mapping using GIS-based statistical models and remote sensing data in tropical environment. Sci. Rep. 2015, 5, 9899. [CrossRef]

19. Chatterjee, P.; Athawale, V.M.; Chakraborty, S. Selection of materials using compromise ranking and outranking methods. Mater. Des. 2009, 30, 4043-4053. [CrossRef]

20. Rao, R.V. A decision making methodology for material selection using an improved compromise ranking method. Mater. Des. 2008, 29, 1949-1954. [CrossRef] 
21. Jahan, A.; Mustapha, F.; Ismail, Y.; Sapuan, S.M.; Bahraminasab, M. A comprehensive VIKOR method for material selection. Mater. Des. 2011, 32, 1215-1221. [CrossRef]

22. Altuntas, S.; Selim, H.; Dereli, T. A fuzzy DEMATEL-based solution approach for facility layout problem: A case study. J. Adv. Manuf. Technol. 2014, 73, 749-771. [CrossRef]

23. Chan, J.W.K. Application of grey relational analysis for ranking material options. J. Comput Appl Technol. 2006, 26, 210-217. [CrossRef]

24. Chan, J.W.K.; Tong, T.K.L. Multi-criteria material selections and end-of-life product strategy: Grey relational analysis approach. Mater. Des. 2007, 28, 1539-1546. [CrossRef]

25. Rezaei, J. Best-worst multi-criteria decision-making method. Omega 2015, 53, 49-57. [CrossRef]

26. Taflanidis, A.A.; Beck, J.L. Life-cycle cost optimal design of passive dissipative devices. Struct. Saf. 2009, 31, 508-522. [CrossRef]

27. Avikal, S.; Jain, R.; Mishra, P.K. A Kano model: AHP and M-TOPSIS method-based technique for disassembly line balancing under fuzzy environment. Appl. Soft Comput. 2014, 25, 519-529. [CrossRef]

28. Govindan, K.; Shankar, K.M.; Kannan, D. Sustainable material selection for construction industry-A hybrid multi criteria decision making approach. Renew. Sustain. Energy Rev. 2015, 55, 1274-1288. [CrossRef]

29. Tavana, M.; Zareinejad, M.; Di Caprio, D.; Kaviani, M.A. An integrated intuitionistic fuzzy AHP and SWOT method for outsourcing reverse logistics. Appl. Soft Comput. 2016, 40, 544-557. [CrossRef]

30. Ou Yang, Y.P.; Shieh, H.M.; Leu, J.D.; Tzeng, G.V. A novel hybrid MCDM model combined with DEMATEL and ANP with applications. J. Oper. Res. 2008, 5, 160-168.

31. IPCC. Intergovernmental Panel for Climate Change Fourth Assessment Report; Cambridge University Press: Cambridge, UK, 2007.

32. Stern, N. The Economics of Climate Change: The Stern Review; Cambridge University Press: Cambridge, UK, 2007.

33. Committee on Climate Change. Building a Low-Carbon Economy-The UK's Contribution to Tackling Climate Change; The Stationery Office: London, UK, 2008.

34. BP Statistical Review of World Energy. Available online: http://www.bp.com/content/dam/bp/pdf/ StatisticalReview-2012/statistical_review_of_world_energy_2012.pdf (accessed on 20 September 2018).

35. Tian, Y.; Zhou, X.; Lin, S.; Ji, X.; Bai, J.; Xu, M. Syngas production from air-steam gasification of biomass with natural catalysts. Sci. Environ. 2018, 645, 518-523.

36. Chianese, S.; Fail, S.; Binder, M.; Rauch, R.; Hofbauer, H.; Molino, A.; Blasi, A.; Musmarra, D. Experimental investigations of hydrogen production from $\mathrm{CO}$ catalytic conversion of tar rich syngas by biomass gasification. Cat. Today 2016, 277, 182-191. [CrossRef]

37. Zhou, Y.; Hao, F.; Meng, W. Scenario analysis of energy-based low-carbon development in China. J. Environ. Sci. 2014, 26, 1631-1640. [CrossRef] [PubMed]

38. Chen, Q.; Kang, C.; Xia, Q. Power generation expansion planning model towards low-carbon economy and its application in China. IEEE Trans. Power Syst. 2015, 25, 1117-1125. [CrossRef]

39. Krishnan, V.; McCalley, J.D. The role of bio-renewables in national energy and transportation systems portfolio planning for low carbon economy. Renew. Energ. 2016, 91, 207-223. [CrossRef]

40. Zhong, J. Study on Uncertain Multi-Objective Optimization and Multi-attribute Decision Making for Low Carbon Power Supply Planning; Yanshan University: Qinhuangdao, China, 2015.

41. Saaty, T.L. Decision Making with Dependence and Feedback: The Analytic Network Process; Rws Publications: Pittsburgh, Pennsylvania, 1996.

42. Saaty, T.L. Fundamentals of the analytic network process. In Proceedings of the ISAPH International Symposium on the Analytic Hierarchy Process, Kobe, Japan, 12-14 August 1999.

43. Hsu, C.H.; Wang, F.K.; Tzeng, G.H. The best vendor selection for conducting the recycled material based on a hybrid MCDM model combining DANP with VIKOR. Resour. Conserv. Recycl. 2012, 66, 95-111. [CrossRef]

44. Liu, H.C.; You, J.X.; Fan, X.J. A novel hybrid multiple criteria decision making model for material selection with target-based criteria. Mater. Des. 2016, 60, 380-390. [CrossRef]

45. Chiu, W.Y.; Tzeng, G.H.; Li, H.L. A new hybrid MCDM model combining DANP with VIKOR to improve e-store business. Knowl. Based Syst. 2013, 37, 48-61. [CrossRef]

46. Opricovic, S. Multi-Criteria Optimization of Civil Engineering Systems. Ph.D. Thesis, Faculty of Civil Engineering, Belgrade, Serbia, 1998.

47. Opricovic, S.; Tzeng, G.-H. Multicriteria planning of post-earthquake sustainable reconstruction. Comput.-Aided Civ. Infrastruct. Eng. 2002, 17, 211-220. [CrossRef] 
48. Opricovic, S.; Tzeng, G.H. Compromise solution by MCDM methods: A comparative analysis of VIKOR and TOPSIS. Eur. J. Oper. Res. 2004, 156, 445-455. [CrossRef]

49. Tian, G.; Zhou, M.; Li, P. Disassembly sequence planning considering fuzzy component quality and varying operational cost. IEEE Trans. Autom. Sci. Eng. 2018, 15, 748-760. [CrossRef]

50. Pi-Fang, H. Evaluation of advertising spokespersons via the ANP-GRA selection model. J. Grey Syst. 2009, $21,35-48$.

51. Sanchez-Lozano, J.M.; Fernandez-Martinez, M. Near-Earth object hazardous impact: A multi-criteria decision making approach. Sci. Rep. 2006, 6, 37055. [CrossRef] [PubMed]

52. Feng, Y.; Zhang, Z.; Tian, G.; Lv, Z.; Tian, S.; Jia, H. Data-driven accurate design of variable blank holder force in sheet forming under interval uncertainty using sequential approximate multi-objective optimization. Future Gener. Comput. Syst. 2018, 86, 1242-1250. [CrossRef]

C 2018 by the authors. Licensee MDPI, Basel, Switzerland. This article is an open access article distributed under the terms and conditions of the Creative Commons Attribution (CC BY) license (http://creativecommons.org/licenses/by/4.0/). 